\title{
Numerical study for the use of different nozzle shapes in microscale channels for producing clean energy
}

\author{
A. H. Elbatran • O. B. Yaakob • Yasser M. Ahmed • \\ H. M. Shabara
}

Received: 14 April 2014/ Accepted: 16 December 2014/Published online: 9 January 2015

(C) The Author(s) 2014. This article is published with open access at Springerlink.com

\begin{abstract}
Nowadays, most rural and hilly areas use the small and microscale plants to produce electricity; it is cheap, available and effective. Utilizing hydrokinetic turbines in flow of rivers, canal or channel to produce power has been a topic of considerable interest to researchers for past years. Many countries that are surrounded by irrigation or rainy channels have a great potential for developing this technology. Development of open flow microchannels that suit these countries has a main problem, which is low velocity of current appears, hence deploying nozzle in-stream open channels flow is the brilliant method for increasing the channels current flow systems' efficiency. The nozzle is believed to have an ability of concentrating the flow direction whilst increasing the flow velocity. In this study, the effects of nozzle geometrical parameters such as diameter ratio, nozzle configuration and nozzle edges shape on the characteristics of the flow in the microscale rectangular channels have been investigated numerically, using a finite volume RANSE code ANSYS CFX. The physical parameters were reported for a range of diameter ratio $\left(d_{2} / d_{1}\right)$ from $5 / 6$ to $1 / 6$ and nozzle length $\left(L_{\mathrm{n}}\right)$ of $0.8 \mathrm{~m}$ for various nozzle shapes. We also proposed a new approach which is the use of NACA 0025 aerofoils as a deploying nozzle in channels. The results of the current study showed that, although the decrease in the nozzle diameter ratio led to an increase of the flow velocity through the channel but it
\end{abstract}

\footnotetext{
A. H. Elbatran · Y. M. Ahmed · H. M. Shabara Faculty of Mechanical Engineering, Universiti Teknologi Malaysia, 81310 Skudai, Johor, Malaysia

O. B. Yaakob $(\bowtie)$. Y. M. Ahmed

Marine Technology Center, Universiti Teknologi Malaysia, 81310 Skudai, Johor, Malaysia

e-mail: omar@fkm.utm.my; haaaly2@live.utm.my
}

can affect drastically on the flow pattern, especially the free surface, at the nozzle area, which may reduce the amount of the generated power, thus the study concluded with optimum diameter ratio, which was $2 / 3$. The flow patterns improved with the curved edges shape; the NACA shape gave the most preferable results.

Keywords Microscale channel - Deploying nozzle · Clean energy production diameter ratio - Convergence system - Convergence-divergence system - NACA shape

\section{Introduction}

The sustainable environment occupied the interests of researchers nowadays, because of the rapid growth in the level of greenhouse gas emissions and the fuel cost crisis [1]. Renewable energy presents the efficient solution for the future to achieve a perfect connection between renewable energy and sustainable development [2, 3]. Hydrokinetic power is now renowned as one of the most important clean power resource in the world, especially microapplications, which can be utilized in remote and electrification sites [4-6]. Recently, the researchers gave more attention to the amount of harnessed power in the open channels current flow. Thus, references [7-14] presented various analytical and numerical methods in detail to estimate the tidal current potential power in channels. Instream technology is a young type of small and micro hydro-power system and it is based on deploying of the hydrokinetic turbines in flow of rivers or canal to generate energy, this type of application is a potential to the future of power generation $[15,16]$. Harnessing kinetic energy from flowing of water in open channels can optimize existing facilities such as weirs, barrages and falls [17]. 
Research has focused on studying the water stream technology from both flow and turbines systems points of view by considering the improvements on the open channel flow and the suitable turbine systems, which can be utilized in these micro/small channels to be used in the micro/small power production. The free stream flow systems normally need a higher amount of mass flow with low velocities and pressures to be able to extract energy, but the conventional current turbines are more suitable for high pressure and flow rate [18]. Hence, many studies investigated a unique and new technology design and configurations to capture as much as kinetic energy. Using the nozzle is the most efficient choice to accelerate the flow and it can be increased by the harnessed power. This nozzle can be utilized in stream of the microchannel flow or ducted around turbines. Khan et al. [19] carried out analytical and numerical studies to accelerate the flow by deploying convergent nozzles for run-of-river turbines in open channels. Kirke [20] investigated a ducted turbine and he gained more power than the open turbine. Furukawa et al. [21] presented design parameters of ducted Darrieus-type water turbine principle for high performance at low-head micro hydropower. Shimokawa et al. [22] proposed more simplified runner casing of Darrieus turbines and examined the inlet nozzle and the small upper-casing by experiment to improve turbine performance for low-head small power scales. Our present work is similar to the work of Khan et al. [19] in utilizing nozzle in microscale channels. Deploying nozzle in channels causes acceleration of the flow and increases the water kinetic energy. The power extracted from channels mainly depends on the velocity of the in-stream water flow, thus the geometrical parameters of the nozzles have major effects on the flow patterns and velocity. By focusing only on one parameter, which was the inlet angle of the convergence nozzle, Khan et al. [19] studied the flow patterns through the velocity and pressure behavior contours. The present study investigated the flow characteristics in micronozzle channels through parametric study of the nozzle geometry to utilize in the small/micro power generation. Here we take into account the free surface and turbulence effects when assessing the nozzle channel potentials. Our aim is to study the characteristics of the nozzle in a microchannel flow with a view of extracting renewable energy. To achieve this aim, this research focused on determining the flow field pattern, water velocity values, pressure distribution, turbulence effects, volume flow rate and the amount of power that could be captured with respect to varying geometrical parameters of the deploying nozzles; also, these included the effects of the free surface. The numerical study was performed using the commercial CFD code ANSYS CFX.

\section{Microscale of channel nozzle configuration modeling}

Dimensions of microscale channels and deploying nozzles

The geometry of the microscale nozzle channel model is shown in Fig. 1, where $L=20 \mathrm{~m}$ indicates the overall length of channel, $W=0.6 \mathrm{~m}$ is the width of the channel, $T=0.4 \mathrm{~m}$ is the channel inlet water level, and $h=1.2 \mathrm{~m}$ is the channel depth. The channel has a rectangular cross section and the nozzle is positioned in the middle of the channel plan.

Also, Fig. 1 illustrates the geometry of the deploying nozzle, where $L_{\mathrm{n}}$ is the length of the nozzle; $d_{1}$ and $d_{2}$ are the inlet and nozzle diameters, respectively, while the parameters of the five different sets of nozzles are shown in Table 1. The nozzle was located in the middle of the channels to assess the behavior of up and down streams of the nozzle.

Fig. 1 Microscale channel physical model

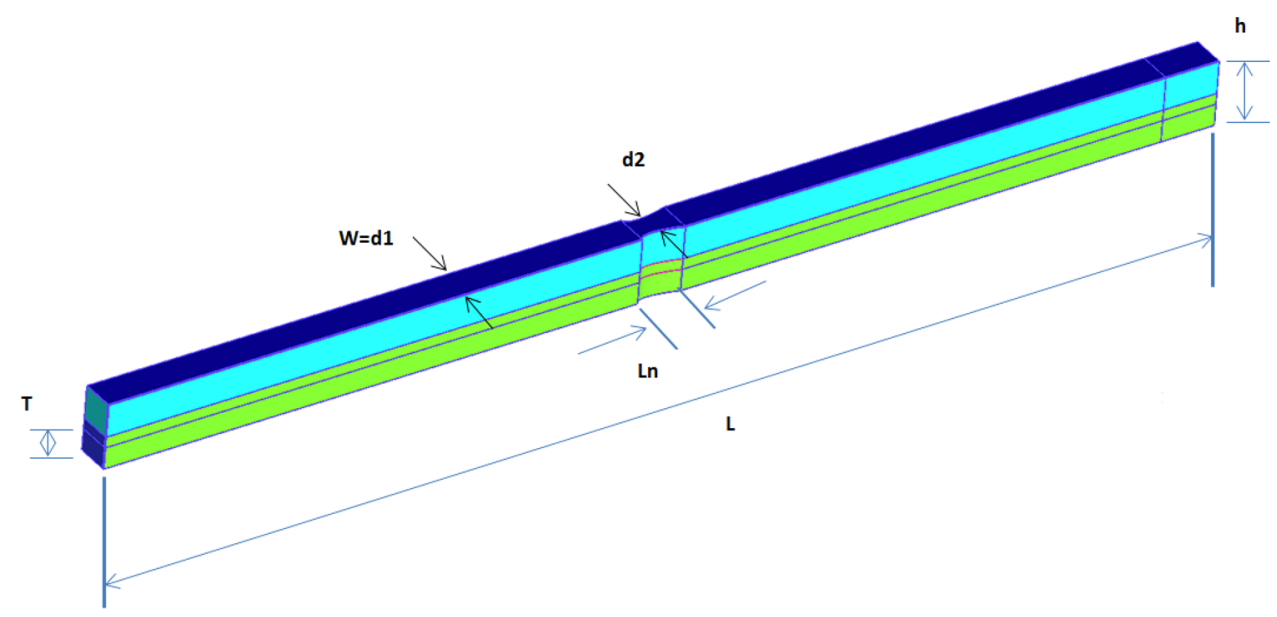


Table 1 Nozzle main geometrical parameters were tested in the current study

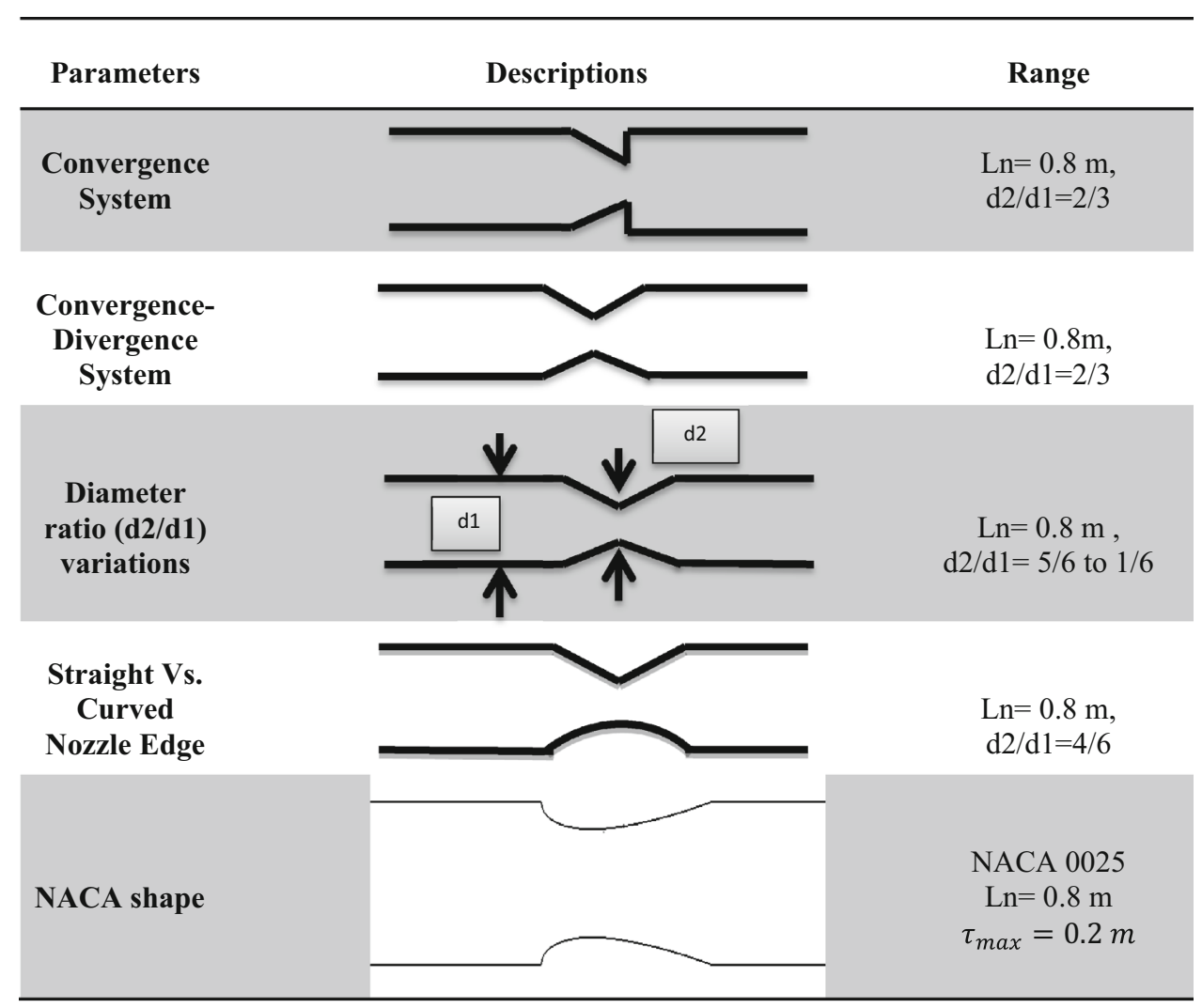

\section{Grid generation}

The grid generator of the RANSE code (ICEM CFD) was used for meshing the channel with structured hexahedron grids. The computational domain of the channels was meshed with structured hexahedral mesh elements of the same sizes for all the cases. Several computational grids were tested in this study to check the solution sensitivity as shown in Table 2, and ultimately the mesh chose the contained structured hexahedral elements that had been used for channels and nozzles in the current study, as shown in Fig. 2. Hence, the total number of elements on nozzle channel configuration system was about 2,068,978

Table 2 Grid dependence study was conducted for case of diameter ratio $\left(d_{2} / \mathrm{d} 1\right)=2 / 3$

\begin{tabular}{lcl}
\hline Case no. & $\begin{array}{l}\text { No. of mesh } \\
\text { elements }\end{array}$ & $\begin{array}{l}\text { Maximum velocity } \\
\text { along channel }(\mathrm{m} / \mathrm{s})\end{array}$ \\
\hline 1 & 250,862 & 1.860 \\
2 & 512,118 & 1.832 \\
3 & $1,128,086$ & 1.815 \\
4 & $1,688,672$ & 1.805 \\
5 & $2,068,978$ & 1.790 \\
6 & $2,268,614$ & 1.789 \\
7 & $2,567,818$ & 1.790 \\
\hline
\end{tabular}

which is the case no. 5 in Table 2, there is no change in the velocity values after these mesh elements numbers.

\section{Computational method}

In this research, finite volume method was used for discretizing the governing equations in ANSYS CFX. The convective terms were discretized using second-order upwind scheme, and the pressure was interpolated using linear interpolation scheme, while the central difference scheme was utilized for diffusion terms. For the pressurevelocity coupling, the semi-implicit methods for pressurelinked equation (SIMPLE) were utilized. The $k-\varepsilon$ SST turbulence model was used for turbulence modeling. Also, different turbulence models were used with comparison of analytical calculations of energy equations, but the best results were obtained by the $k-\varepsilon$ SST turbulence model as shown in Table 3. Convergence was monitored through making dimensionless residual sum for all variables across the computational points. The minimum residual sum for convergence was set to $1 \times 10^{-6}$. The inlet boundary condition was set with constant mean velocity normal to the inlet. The inlet velocity and water depth at the inlet boundary of the different microchannels in this study were $1 \mathrm{~m} / \mathrm{s}$ and $0.4 \mathrm{~m}$, respectively. The inlet velocity was chosen that suitable for operating within Malaysian Ocean, 


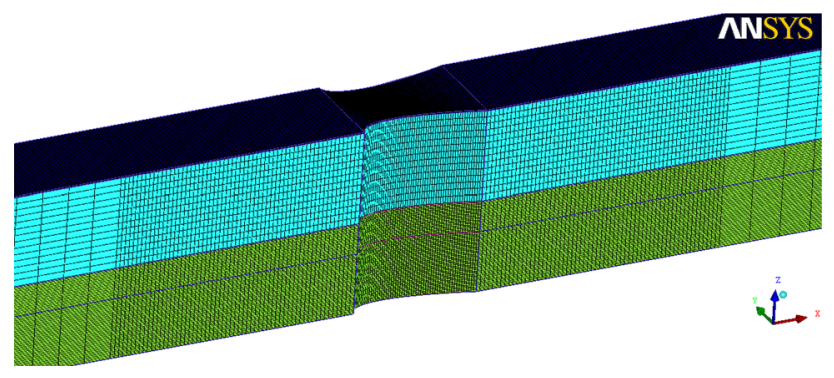

Fig. 2 The meshed nozzle-channel configuration

which has low-speed current present $(1.0 \mathrm{~m} / \mathrm{s}$ average) [23]. The outlet boundary condition was specified by the outflow. The working fluid was water with the density of $1,000 \mathrm{~kg} / \mathrm{m}^{3}$, and kinematic viscosity of $1 \times 10^{-6} \mathrm{~m}^{2} / \mathrm{s}$, the reference pressure was $1 \mathrm{bar}$, the walls were set to a no slip condition.

\section{Governing equations}

The mathematical description of the free surface flow in ANSYS CFX is based on the homogenous multiphase Eulerian fluid approach. In this approach, both fluids (air and water) share the same velocity fields and other relevant fields such as temperature, turbulence, etc., and they are separated by a distinct resolvable interface. The governing equations for the unsteady, vicious, turbulent flow are the Navier-Stokes equations, which can be written in the following form:

$$
\begin{aligned}
\frac{\partial}{\partial t}(\rho)+\frac{\partial}{\partial x_{i}}\left(\rho u_{i}\right)= & 0.0 \\
\left(\rho u_{i}\right)+\frac{\partial}{\partial x_{i}}\left(\rho u_{i} u_{j}\right)= & -\frac{\partial p}{\partial x_{i}}+\frac{\partial}{\partial x_{i}}\left(-\rho \overline{u_{i}^{\prime} u_{j}^{\prime}}\right) \\
& +\frac{\partial}{\partial x_{j}}\left[\mu\left(\frac{\partial u_{i}}{\partial x_{j}}+\frac{\partial u_{j}}{\partial x_{i}}-\frac{2}{3} \delta_{i j} \frac{\partial u_{l}}{\partial x_{l}}\right)\right]
\end{aligned}
$$

where

$-\rho \overline{u_{i}^{\prime} u_{j}^{\prime}}=\mu_{t}\left(\frac{\partial u_{i}}{\partial x_{j}}+\frac{\partial u_{j}}{\partial x_{i}}\right)-\frac{2}{3}\left(p k+\frac{\partial u_{i}}{\partial x_{i}}\right) \delta_{i j}$,

and $\rho=\sum_{\alpha=1}^{2} r_{\alpha} \rho_{\alpha}, \mu=\sum_{\alpha=1}^{2} r_{\alpha} \mu_{\alpha}, \sum_{\alpha=1}^{2} r_{\alpha}=1$.

The SST turbulent model can be expressed in the following mathematical form:

$\frac{\partial(p k)}{\partial t}+\frac{\partial}{\partial x_{i}}\left(p k u_{i}\right)=\frac{\partial}{\partial x_{j}}\left(\Gamma_{k} \frac{\partial k}{\partial x_{j}}\right)+G_{k}-Y_{k}$

$\frac{\partial(p \omega)}{\partial t}+\frac{\partial}{\partial x_{i}}\left(p \omega u_{i}\right)=\frac{\partial}{\partial x_{j}}\left(\Gamma_{\omega} \frac{\partial \omega}{\partial x_{j}}\right)+G_{\omega}-Y_{\omega}+D_{\omega}$

In the previous two equations, $\Gamma_{k}$ and $\Gamma_{\omega}$ represent the effective diffusivity for $k$ and $\omega . G_{k}$ represents the generation of turbulence kinetic energy due to mean velocity gradients, and $G_{\omega}$ represents the generation of $\omega . Y_{k}$ and $Y_{\omega}$ represent the dissipation of $k$ and $\omega$ due to turbulence. $D_{\omega}$ represents the cross-diffusion term.

Velocity is the corner stone parameter to extract current power from the channels water flow. The natural velocity of the channels is governed by Chezy's and Manning's formulae. Manning gave accepted values in this manner; Eq. (7) is termed the Manning equation [24]:

$V=\frac{R^{2 / 3} S^{1 / 2}}{n}$

where $V$ is the velocity of the flow, $R$ is the hydraulic radius of the channel cross section and it is termed by dividing the cross-sectional area $(A)$ of the channel with its wetted perimeter $(P), S$ is the bed slope of the channel and " $n$ " is the Manning resistance coefficient, the value of " $n$ " is depending on the surface material of the channels, its values are varying from 0.011 to 0.0 [25]. The value of the incoming flow of the current channel is $1 \mathrm{~m} / \mathrm{s}$.

The maximum extractable power available from flowing kinetic water in channels is presented in Eq. (8):

$P=0.5 \rho A V^{3}$

where $P$ is the power, $\rho$ is the density of water, $A$ the sectional area of the flow and $V$ is the flow stream velocity. The maximum achievable power extraction is strongly associated with the flow velocity as shown in Eq. (8), thus utilizing nozzle in the channel can enhance the flow to extract as much as power from the flowing water. When the

Table 3 Comparison between various turbulence models and analytical calculations for detecting average velocity at the nozzle plan of the channel for case of diameter ratio $\left(d_{2} / d_{1}\right)=2 / 3$

\begin{tabular}{llllll}
\hline Theoretical and turbulence model criteria & Analytical results & \multicolumn{3}{l}{ Turbulence model results } \\
\cline { 2 - 5 } & Energy equation (Bernoulli's equation) & $k-\varepsilon$ SST & $k-\varepsilon$ SSG & $k-\varepsilon$ EARSM & $k-\omega$ \\
\hline Nozzle plan cross section mean velocity $(\mathrm{m} / \mathrm{s})$ & 1.720 & 1.680 & 1.977 & 2.045 & 1.892 \\
\hline
\end{tabular}




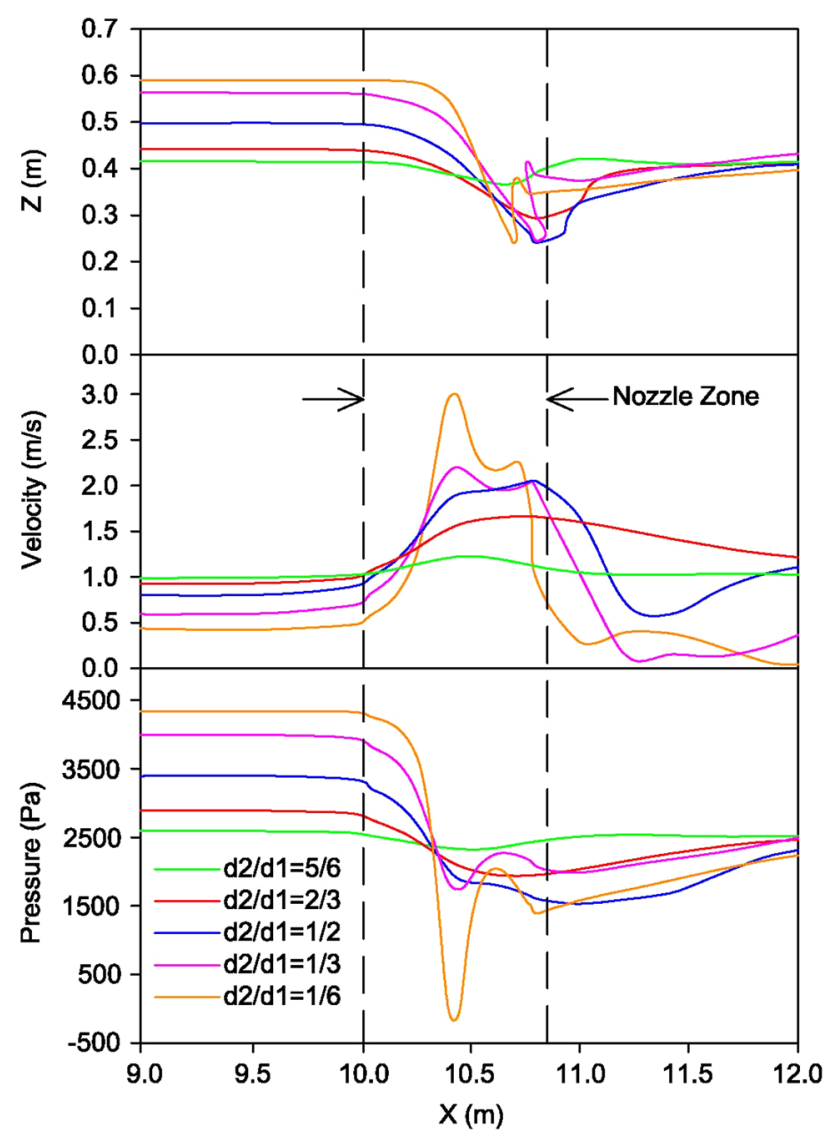

Fig. 3 Free surface positions, velocity and pressure variations along central plane of the channel for different nozzle diameter ratio $\left(d_{2} / d_{1}\right)$

nozzle was deployed, the area of the channel changed, so the velocity computing through nozzles can be determined based on continuity equation, which is stated in Eq. (9), the mass flow per unit time through the nozzle is given by:

$m=\rho V A=\rho V_{1} A_{1}=\rho V_{2} A_{2}$

where $\rho=$ constant (incompressible flow).

\section{Results and discussion}

Generally, the nozzles accelerate the flow which caused the velocity to increase at the nozzle plane, while the pressure was decreased in accordance with continuity and energy equations concept. Here we investigated the changes in flow pattern behaviors and other parameters, especially free surface flow effects and turbulence effects, based on these geometrical changes. Thus, velocity, pressure, free surface position, turbulence effects and harnessed power for abovementioned cases were simulated and tested. The results were plotted at $X-Y$ plane for $Z=0.15 \mathrm{~m}$, these results of all cases are presented separately in the subsequent paragraphs.

\section{Diameter ratio effects}

Regarding to continuity equation (9) for steady incompressible flow, the velocity will increase with the decreasing of the area of the contraction. Figure 3 illustrates the velocity, pressure and free surface along a central plane through the channel with variations of diameter ratios of the deploying nozzle. The graph showed that the peak values of velocity were obtained at the smallest value of the nozzle area, but in these cases the maximum velocity exploited small cross-sectional and longitudinal areas of channel as shown in Figs. 3 and 4. This is due to the sudden drop in velocity behind the nozzle orifice. This velocity drop recorded significant values for diameter ratio over $1 / 2$. Moreover, the flow velocities in the cases of $2 / 3$ and $1 / 2$ diameter ratios were maintained in the longer area; the velocity contours are shown in Fig. 4. The free surface decreased when the diameter ratio was reduced, and it reached near to $50 \%$ of the channel draft in cases over $2 / 3$. The reduction of the nozzle diameter ratio was due to increment in the pressure differences along the nozzle until the pressure reached to small and negative values, especially for cases of $1 / 2,1 / 3$ and $1 / 6$ diameter ratios. This behavior has a negative impact on the channels flow characteristics; it can be caused by cavitation in the presence of turbine.

Determining the area occupied by the water with maximum velocity is dependent on free surface of the channel especially for microscale; it is important and could be used as a direct measure of the mass flow rate of water. Table 4 displays the main flow characteristics in the channels at the nozzle for different diameter ratios. The flow rates get decreased with the reduction in diameter ratio $\left(d_{2} / d_{1}\right)$ although the maximum velocity occurred at these ratios; this happened because of the cross-sectional area effects. The last two cases described in Table 4 have negative impacts on the water flow streams in the channels; and the small flow rate can cause blockage. The $2 / 3$ diameter ratio achieved maximum flow rates because it has optimum area and optimum mean velocity, thus the highest power was recorded at $2 / 3$ ratio, which was $334.28 \mathrm{~W}$.

The adequate diameter ratio of the nozzle in the channel is dependent not only on the velocity values, cross-sectional area to capture more power but also on the flow velocity fluctuations with respect to time, which means the flow turbulence. Turbulence causes higher frictional losses leading to higher pressure drop [24]. Thus turbulence is an important factor to consider when examining the effect of varying nozzle diameter ratios on the flow patterns. Turbulence intensity (TI) is one of the most important formulas for measuring turbulence; it is defined as the root mean square of turbulence velocity variations normalized with respect to the channel mean velocity. The previous 


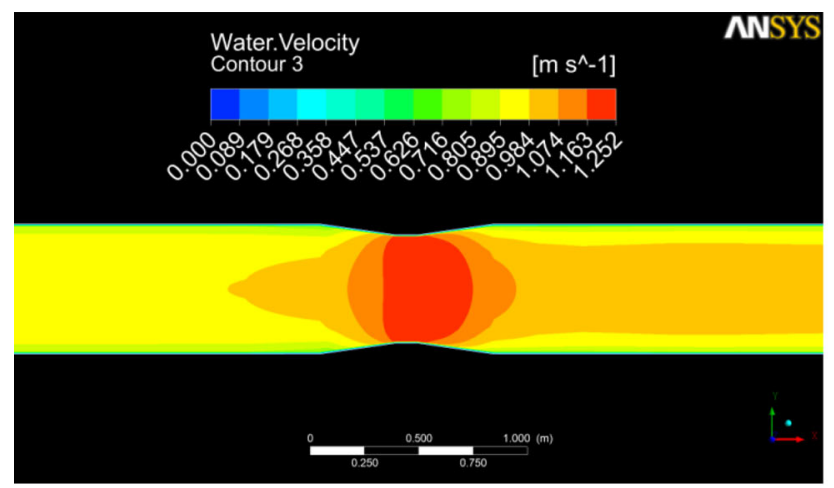

$(\mathrm{d} 2 / \mathrm{d} 1=5 / 6)$

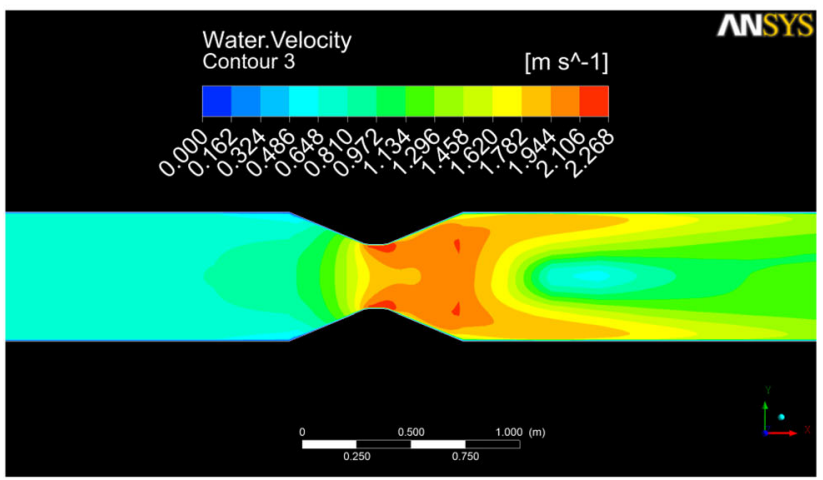

$(\mathrm{d} 2 / \mathrm{d} 1=1 / 2)$

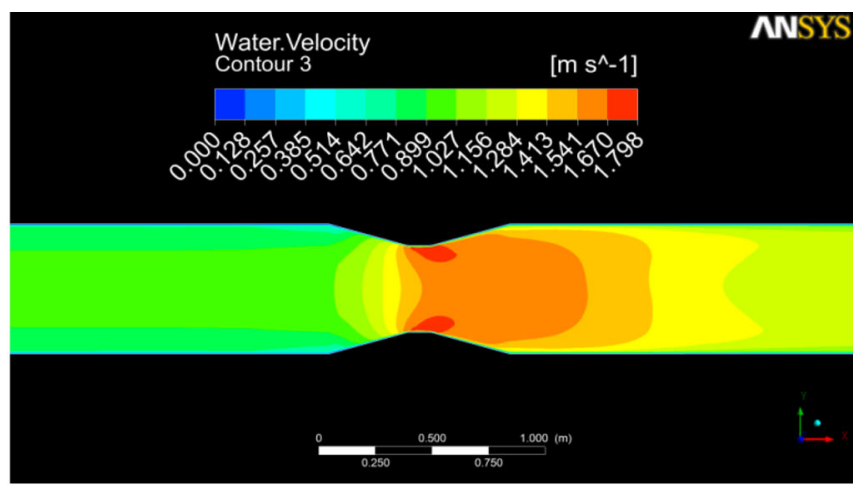

$(\mathrm{d} 2 / \mathrm{d} 1=2 / 3)$

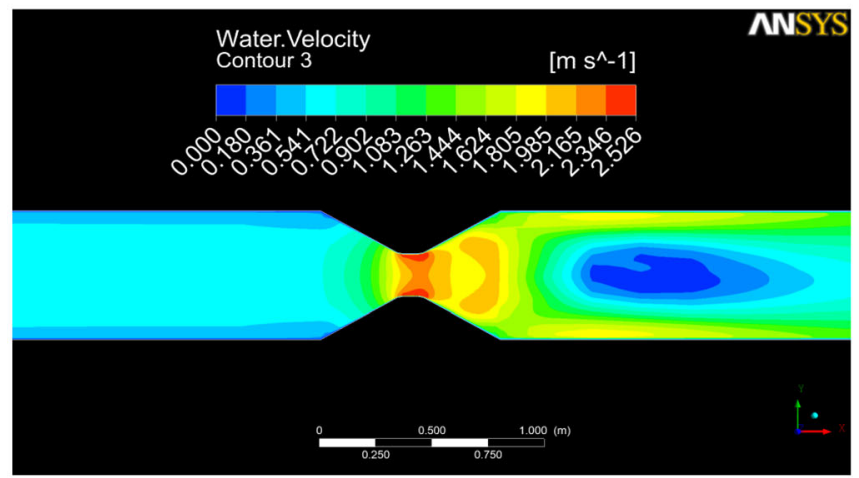

$(\mathrm{d} 2 / \mathrm{d} 1=1 / 3)$

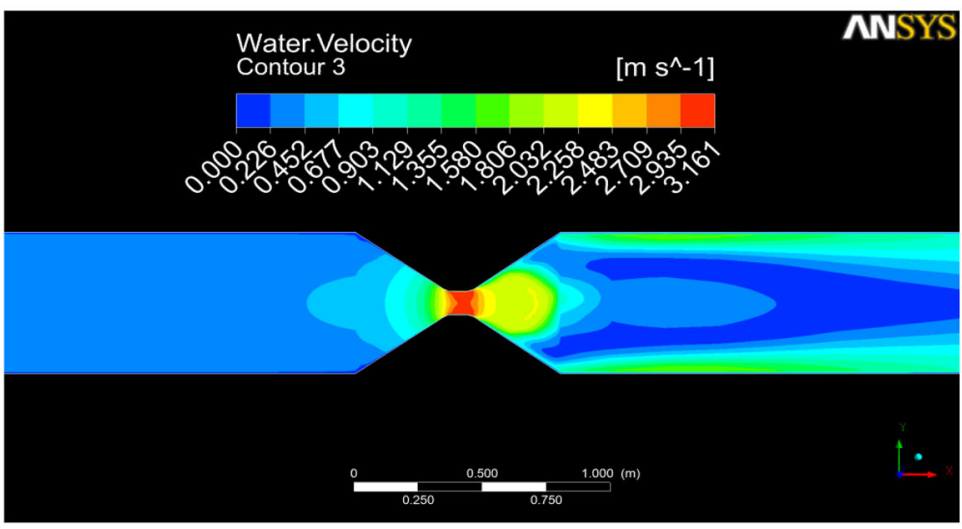

$(\mathrm{d} 2 / \mathrm{d} 1=1 / 6)$

Fig. 4 Water velocity contours showing the flow of water along nozzle-channel for various nozzle diameter ratio $\left(d_{2} / d_{1}\right)$

studies which measured TI in channels showed that TI varied from $5 \%$ on the free surface to about $15 \%$ near to the bed [26].

Figure 5 illustrates the values of TI along the channel and nozzle plane at varying nozzle diameter ratio. The results indicate that the TI increased behind the nozzle with decrease in the area of contraction. The maximum values of TI are about 500, 250 and $50 \%$ for ratio of 1/6,1/3 and $1 / 2$, respectively. In these cases, the flow became more highly turbulent and gave massive values of the TI, which leads to highest losses in the channels. In contrast, the ratios of $5 / 6$ and $2 / 3$ gave accepted values of TI which recorded 3.5 and $10 \%$ as a maximum in the two cases, respectively. This reduces the friction coefficient. From the above analysis and according to all parameters, it was concluded that the optimum value of the diameter ratio $\left(d_{2}\right)$ $\left.d_{1}\right)$ is $2 / 3$.

\section{Convergence and convergence-divergence systems}

It was found from this study, the maximum velocity value that can be obtained in the convergence-divergence system 
Table 4 Nozzle channel flow characteristics and captured power for nozzle diameter ratio variations

\begin{tabular}{llllll}
\hline $\begin{array}{l}\text { Diameter } \\
\text { ratio }\left(d_{2} / d_{1}\right)\end{array}$ & $\begin{array}{l}\text { Cross-sectional area was occupied } \\
\text { by the peak values of velocity }\left(\mathrm{m}^{2}\right)\end{array}$ & $\begin{array}{l}\text { Maximum velocity } \\
\text { along channel }(\mathrm{m} / \mathrm{s})\end{array}$ & $\begin{array}{l}\text { Cross section } \\
\text { mean velocity }(\mathrm{m} / \mathrm{s})\end{array}$ & $\begin{array}{l}\text { Maximum } \\
\text { flow rate }(\mathrm{kg} / \mathrm{s})\end{array}$ & $\begin{array}{l}\text { Harnessed power }(\mathrm{W}) \\
\text { at maximum velocity }\end{array}$ \\
\hline $5 / 6$ & 0.174 & 1.252 & 1.220 & 213.250 & 158.700 \\
$2 / 3$ & 0.141 & 1.790 & 1.680 & 236.880 & 334.280 \\
$1 / 2$ & 0.110 & 2.199 & 1.810 & 199.100 & 326.130 \\
$1 / 3$ & 0.094 & 2.498 & 1.899 & 178.600 & 322.370 \\
$1 / 6$ & 0.040 & 3.160 & 2.498 & 100.000 & 312.500 \\
\hline
\end{tabular}

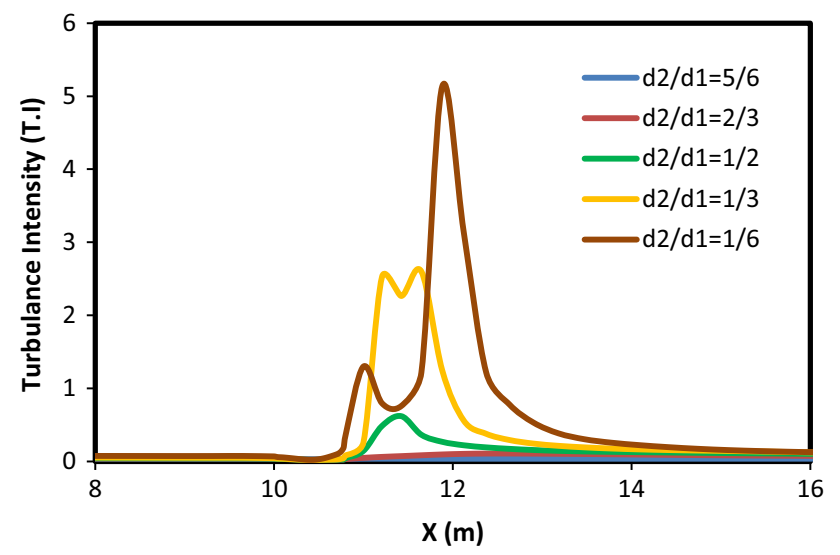

Fig. 5 Turbulence intensity (TI) variations along the central of channel for different nozzle diameter ratio $\left(d_{2} / d_{1}\right)$

was more than convergence system. In addition, the peak velocity for this configuration occupied the larger area of channel as shown in Fig. 6. This is the point of interest, which aimed to obtain as much as area with high velocity to get more harnessed current power. Furthermore, Fig. 7 indicated that the free surface and pressure values were the same in two cases, because they have the same area of contraction. The study concluded that the convergencedivergence system increased the available mean velocity across nozzle leading to an increase in captured power.
Convergence-divergence system developed the flow pattern properties behind the nozzle, especially at the nozzle end corner. On the other hand, convergence indicated zero velocity values at this location as shown in the velocity contours of Fig. 6. Moreover, the flow in this area of the channel behind the nozzle became more turbulent that it has a negative effect on the flow stream. Figure 8 shows the contours of water turbulence kinetic energy, which expressed about the velocity variations with respect to time. The figure described undesirable behavior of turbulence flow at these corners of the outlet nozzle, and this turbulence area was absent in the case of convergencedivergence system.

\section{Nozzle edge shapes effects}

The curved and straight edge nozzles were tested with $2 / 3$ nozzle diameter ratio and $0.8 \mathrm{~m}$ length of nozzle. The velocity contour, which is shown in Fig. 9, proved that the curved edges of the nozzle improved the flow patterns through the nozzle, leading to smoother at the boundary walls. Also, it has a larger area of high velocity than straight edges.

Based on the current study, we concluded that the most suitable shape of the nozzle edge was curved; moreover, the convergence-divergence system like as a venturi gave favorable results. Thus NACA airfoil shape [27] was

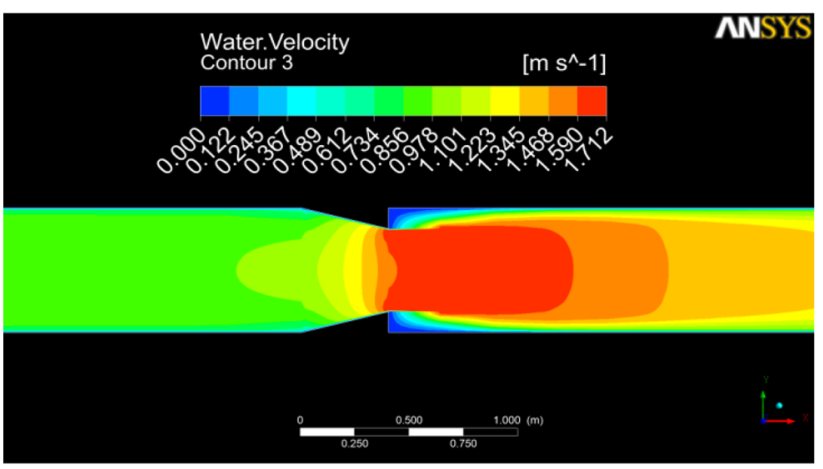

(a)

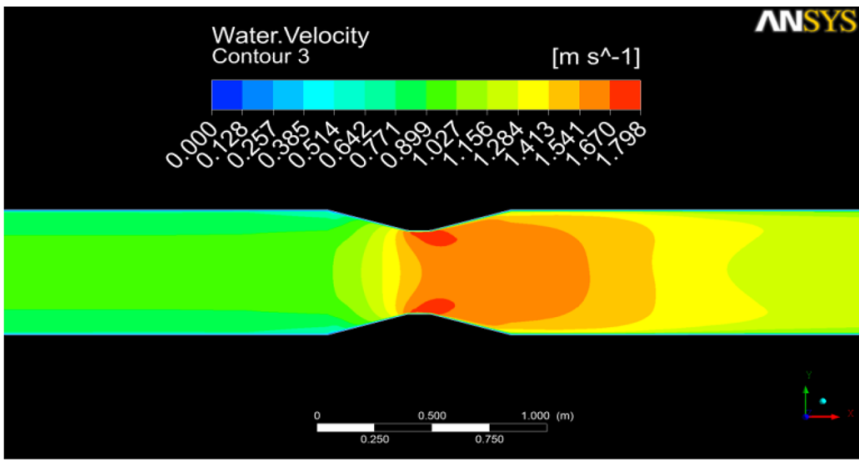

(b)

Fig. 6 Velocity contours showing the flow of water along nozzle channel for cases of a convergence and $\mathbf{b}$ convergence-divergence 


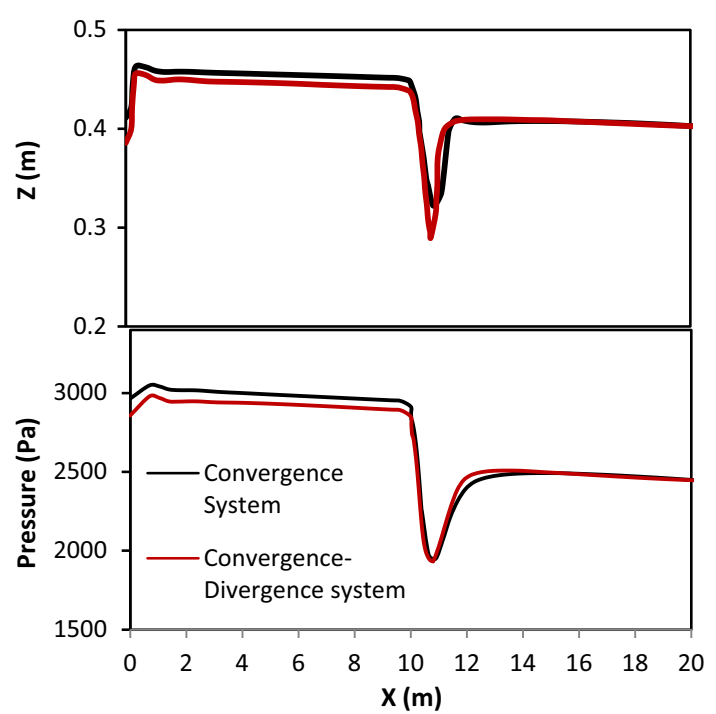

Fig. 7 Free surface positions and pressure variations along the channel for convergence and convergence-divergence systems suggested to be deployed in the channels as a nozzle, since it incorporated these two important parameters. The most ideal section type was symmetrical NACA types, since it is easy to predict and construct on the channels. Here two parallel halves NACA 0025 were used as shown in Fig. 10, where $L_{\mathrm{n}}$ indicates the length which was $0.8 \mathrm{~m}$ and $\tau_{\max }$ is the maximum thickness of the shape, which was equal to $0.1 \mathrm{~m}$ and located at $0.2 \mathrm{~m}$ from the leading edge. The maximum thickness of $0.1 \mathrm{~m}$ was selected to keep the diameter ratio within $2 / 3$ since it was the optimum ratio of the contraction according to our current work, this NACA 0025 shape was drawn by using the equations in Ref. [28]. The flow pattern was developed in case of NACA shape as shown in Fig. 11, which shows the velocity contours along the central of channels. Figure 12 illustrates the effect of NACA, curved and straight nozzle edges on the velocity values along channels; it proved that the peak velocity of NACA shape was more than the two other cases due to the effect of long divergence part, which improved the flow.

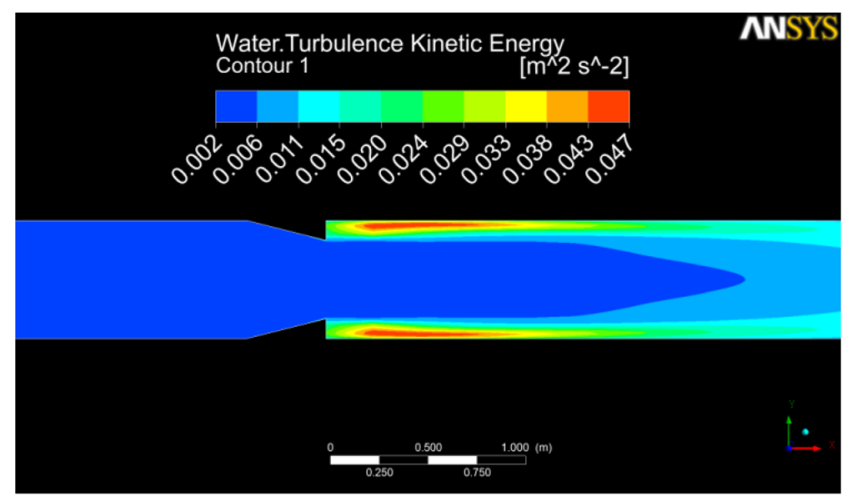

(a)

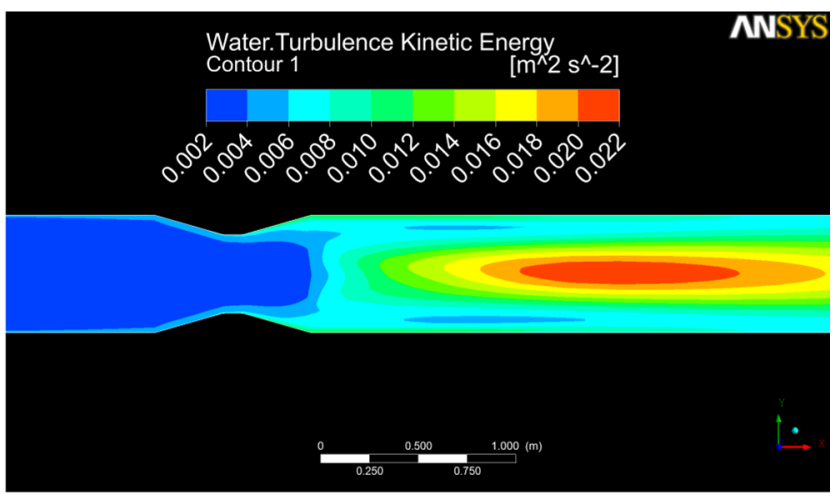

(b)

Fig. 8 Water turbulence kinetic energy contours for cases of a convergence and $\mathbf{b}$ convergence-divergence

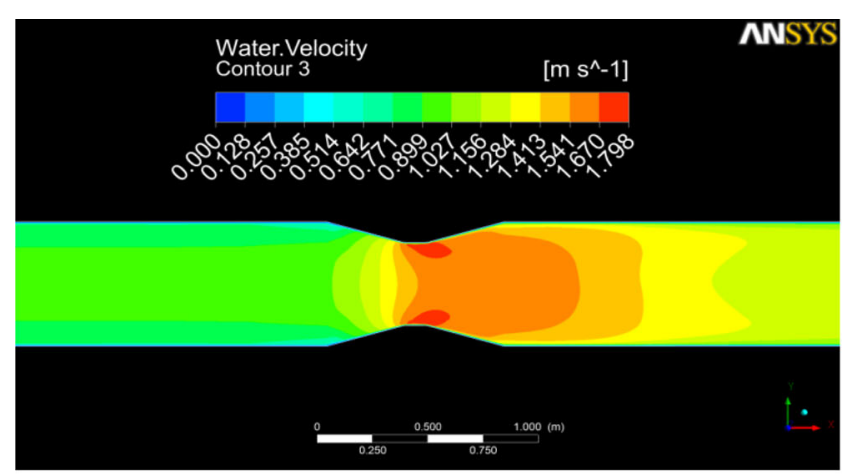

Straight edges

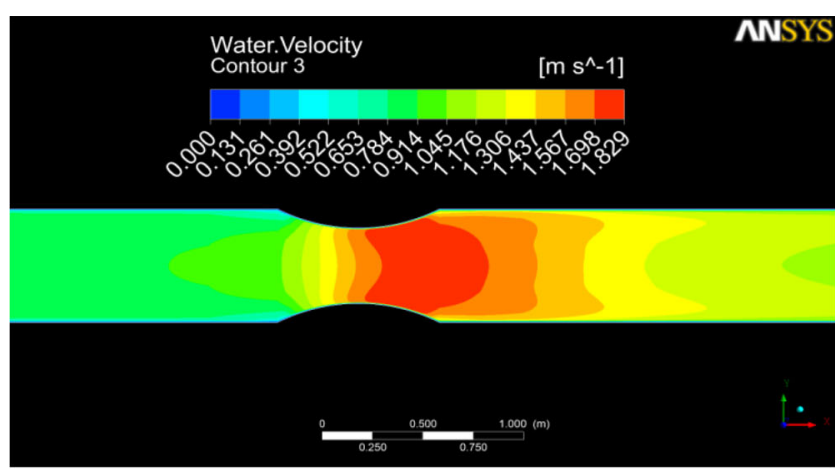

Curved edges

Fig. 9 Velocity contours showing the flow of water through nozzle plan for curved and straight nozzle edges 


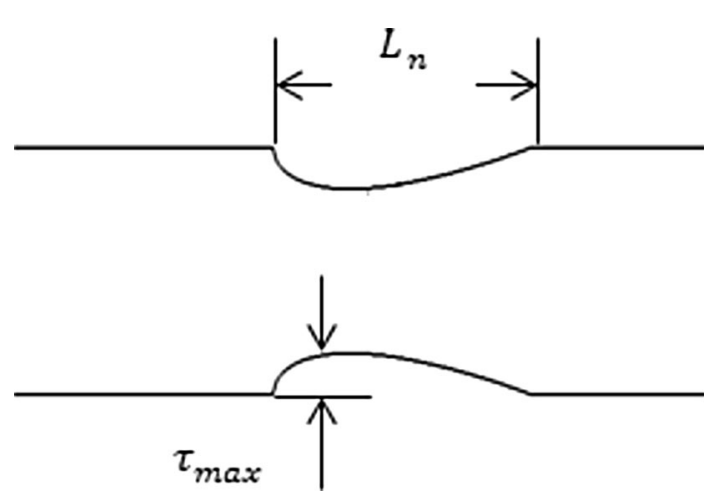

Fig. 10 NACA0025 nozzle

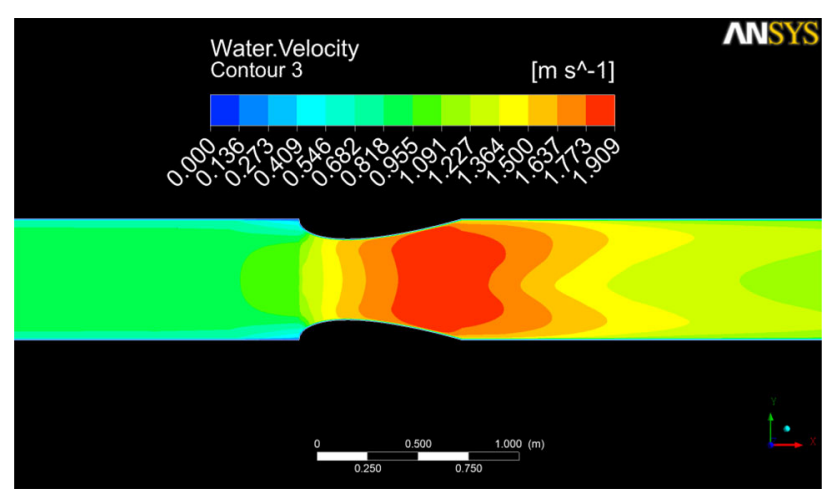

Fig. 11 Velocity contours showing the flow patterns of water along channel for NACA 0025

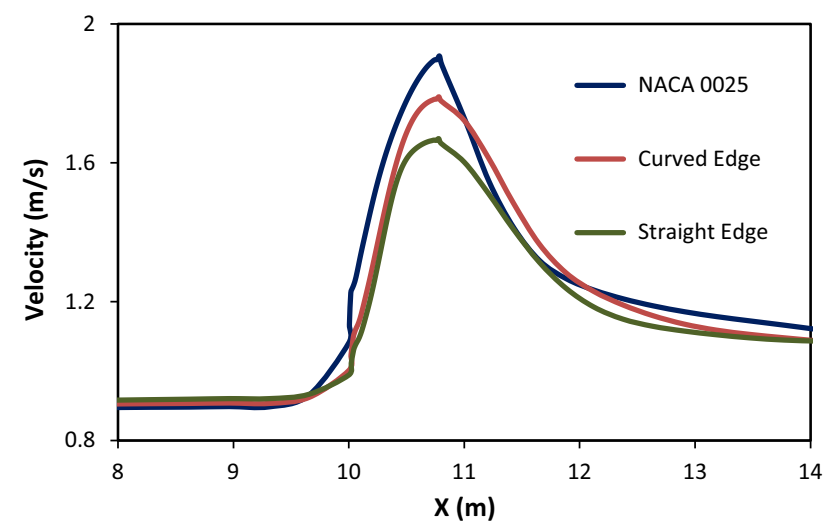

Fig. 12 Velocity values differences along the central plane of channel between NACA 0025, curved and straight nozzle edges

This study was interested in the maximum power, which can be extracted from the microscale channels water streams. Therefore, Fig. 13 shows the peak harnessed power from natural channel to deploying nozzle on channels with straight, curved and NACA shape. The highest power obtained for NACA 0025 was almost $475 \mathrm{~W}$ when the maximum power can be captured in the channel without nozzle that was $120 \mathrm{~W}$.

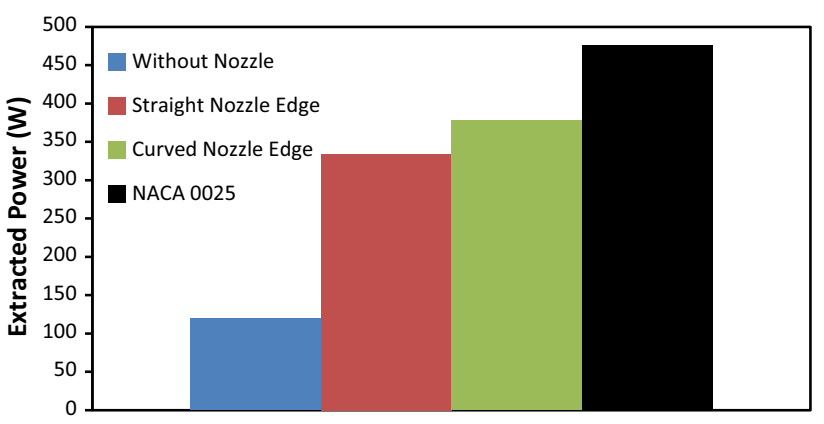

Fig. 13 The potential of harnessed power at different current speed approaching

\section{Conclusion}

Numerical analysis of the nozzle channel configuration was carried out to investigate the effect of nozzle on the flow properties, the extracted current power, velocity, pressure, turbulence and free surface position. The results of this study have been that the flow was accelerated in the channels when the nozzle was utilized. The velocity and the pressure differences increased with the decrease of the diameter ratio of the nozzle, but the free surface position is decreased. The larger area occupied by peak values of velocity was decreased due to the small area of contraction; the flow also became more turbulent. The study indicated that the maximum current power can be extracted for straight shape was $334 \mathrm{~W}$ at optimum diameter ratio of $2 / 3$. The flow patterns developed with curved nozzle edges. This was indicated in the velocity values and the captured power. We offered the new concept of utilizing NACA shape to use as built-in nozzle for channel, it was found that the NACA shape improved the flow characteristics, especially it was achieved progress in velocity values leading to high power generated. In result, the maximum captured current power increased from $120 \mathrm{~W}$ in case of without nozzle to nearly $475 \mathrm{~W}$ for utilizing NACA 0025.

Acknowledgments The authors would like to express our sincere gratitude to Universiti Teknologi Malaysia (UTM) who assisted and provided the capabilities and data compilation for this publication.

Open Access This article is distributed under the terms of the Creative Commons Attribution License which permits any use, distribution, and reproduction in any medium, provided the original author(s) and the source are credited.

\section{References}

1. Sopian, K., Ali, B., Asim, N.: Strategies for renewable energy applications in the organization of Islamic conference (OIC) countries. Renew. Sustain. Energy Rev. 15, 4706-4725 (2011)

2. Yaakob, O.B., Ahmed, Y.M., Elbatran, A.H., Shabara, H.M.: A review on micro hydro gravitational vortex power and turbine systems. Jurnal Teknologi (Sci Eng) 69(7), 1-7 (2014) 
3. Banos, R., Manzo Agugliaro, F., Montoya, F.G., Gil, C., Alcayde, A., Gomez, J.: Optimization methods applied to renewable and sustainable energy: a review. Renew. Sustain. Energy Rev. 15, 1753-1766 (2011)

4. Elbatran, A.H., Yaakob, O.B., Ahmed, Y.M., Shabara, H.M.: Operation, performance and economic analysis of low head micro-hydropower turbines for rural and remote areas: a review. Renew. Sustain. Energy Rev. 43, 40-50 (2015)

5. Hammar, L., Ehnberg, J., Mavume, A., Francisco, F., Molander, S.: Simplified site-screening method for micro tidal current turbines applied in Mozambique. Renew. Energy 44, 414-422 (2012)

6. Liu, H., Ma, S., Li, W., Gu, H., Lin, Y., Sun, X.: A review on the development of tidal current energy in China. Renew. Sustain. Energy Rev. 15, 1141-1146 (2011)

7. Garrett, C., Cummins, P.: The power potential of tidal currents in channels. Proc. R. Soc. A 461, 2563-2572 (2005)

8. Bryden, I.G., Couch, S.J.: How much energy can be extracted from moving water with a free surface: a question of importance in the field of tidal current energy? Renew. Energy 32, 1961-1966 (2007)

9. Sun, X., Chick, J.P., Bryden, I.G.: Laboratory-scale simulation of energy extraction from tidal currents. Renew. Energy 33, 1267-1274 (2008)

10. Atwater, J.F., Lawrence, G.A.: Power potential of a split tidal channel. Renew. Energy 35, 329-332 (2010)

11. Vennell, R.: Estimating the power potential of tidal currents and the impact of power extraction on flow speeds. Renew. Energy 36, 3558-3565 (2011)

12. Vennell, R.: Realizing the potential of tidal currents and the efficiency of turbine farms in a channel. Renew. Energy 47, 95-102 (2012)

13. Walters, R.A., Tarbotton, M.R., Hiles, C.E.: Estimation of tidal power potential. Renew. Energy 51, 255-262 (2013)

14. Draper, S., Adcock, T.A.A., Borthwick, A.G.L., Houlsby, G.T.: Estimate of the tidal stream power resource of the Pentland Firth. Renew. Energy 63, 650-657 (2014)

15. Kumar, A., Ahenkorah, T.A., Caceves, R., Devernay, J.M., Freitas, M., Hall, D., Killingtveiet, A., Liu, Z.: Hydropower, in IPCC special report in renewable energy sources and climate change. Cambridge University press, New York (2011)

16. Chamorro, L.P., Hill, C., Morton, S., Ellis, C., Arndt, R.E.A., Sotiropoulos, F.: On the interaction between a turbulent open channel flow and an axial flow turbine. J. Fluid Mech. 716, 658-670 (2013)
17. Khan, M.J., Bhuyan, G., Iqbal, M.T., Quaicoe, J.E.: Hydrokinetic energy conversion systems and assessment of horizontal and vertical axis turbines for river and tidal applications: a technology status review. Appl. Energy 86, 1823-1835 (2009)

18. Kim, K.-P., Ahmed, M.R., Lee, Y.-H.: Efficiency improvement of a tidal current turbine utilizing a larger area of channel. Renew. Energy 48, 557-564 (2012)

19. Khan, A.A., Khan, A.M., Zahid, M., Rizwan, R.: Flow acceleration by converging nozzles for power generation in existing canal system. Renew. Energy 60, 548-552 (2013)

20. Kirke, B.K.: Tests on ducted and bare helical and straight blade Darrieus hydrokinetic turbines. Renew. Energy 36, 3013-3022 (2011)

21. Furukawa, A., Watanabe, S., Matsushita, D., Okuma, K.: Development of ducted Darrieus turbine for low head hydropower utilization. Curr. Appl. Phys. 10, S128-S132 (2010)

22. Shimokawa, K., Furukawa, A., Okuma, K., Matsushita, D., Watanabe, S.: Experimental study on simplification of Darrieus-type hydro turbine with inlet nozzle for extra-low head hydropower utilization. Renew. Energy 41, 376-382 (2012)

23. Yaakob, O.B.: Marine renewable energy initiatives in Malaysia and South East Asia. In: 13th Meeting of the United Nations Open-ended Informal Consultative Process on Oceans and the Law of the Sea, 29 May-1 June 2012, New York. http://www.un. org/Depts/los/consultative_process/icp13_presentations-abstracts/ 2012_icp_presentation_yaakob.pdf (2012). Accessed 1 April 2014

24. Munson, B.R., Young, D.F., Okishi, T.H.: Fundamentals of fluid mechanics, 5th edn, p. 576. Wiley, New York (2006)

25. Kothandaraman, C.P., Rudramoorthy, R.: Fluid Mechanics and Machinery, 2nd edn, pp. 383-393. New Age International Publishers, New Delhi (2007)

26. Kiely, G.K., McKeogh, E.J.: Experimental comparison of velocity and turbulence in compound channels of varying sinuosity. Channel Flow Resistance: Centennial of Manning's Formula, pp. 393-408. Water Resources Publications, Littleton (1991)

27. Abbott, I.H., Von Doenhoff, A.E., Stivers, L.S., Jr.,: Report no. 824 summary of airfoil data. National Advisory Committee for Aeronautics, Washington (1945)

28. Sproles, D.W.: Computer program to obtain ordinates for NACA Airfoils, NASA Technical Memorandum 474, National Aeronautics and Space Administration. Langley Research Center, Hampton (1996) 